\title{
Las vicisitudes de la protección de la vida y la dignidad humana en el ordenamiento europeo, leídas a la luz de la Declaración Final de la XII Asamblea General de la Academia Pontificia para la Vida (2006) sobre "El embrión humano en la fase de preimplantación"*
}

\author{
Lorenza Violini \\ Catedrática de Derecho Constitucional \\ Università degli Studi di Milano
}

Recibido: 02.05.12

Aceptado: 31.05 .12

Resumen: En el presente trabajo se hace referencia a la protección de la vida humana en el ordenamiento europeo y a la vez se hace un análisis del concepto de dignidad humana en Europa y a su evolución histórica y jurisprudencial. de la vida.

Palabras clave: células totipotentes, Europa, dignidiad humana, protección

Abstract: This paper deals with the protection of human life in European law and also provides an analysis of the concept of human dignity in Europe and its historical and jurisprudential evolution.

Key words: totipotent cells, Europe, Human dignity, Life protection.

1. Todo ordenamiento jurídico, en su dimensión constitucional -momento genético de los conjuntos estatales de referencia-es impulsado por la necesidad de declararse a sí mismo y al mundo sus propios fundamentos. Italia, república democrática, se basa sobre el trabajo, Francia se caracteriza por ser un estado laico, Irlanda invoca a la Trinidad como punto de referencia constitutivo de la nación y así sucesivamente. El fundamento de los fundamentos - perdónese la paradoja- se puede considerar la protección de la dignidad humana, incluida en el pórtico de una Constitución que puede ser considerada como el manifiesto del renacimiento de Europa a partir de las cenizas de la guerra y la tragedia del totalitarismo, la Ley Fundamental con la cual la Alemania derrotada y traspasada en lo más íntimo por el espectáculo de los campos de concentración, lugar de la aniquilación del hombre en favor de la raza, recupera la vida y la dignidad como pueblo.

En la Grundgesetz, de hecho, el pueblo alemán reafirma su fe en la dignidad del hombre, que debe tutelarse sin condiciones y sin excepciones. Del mismo modo, la Declaración de los Derechos Humanos de 1948, punto de referencia de los valores de la Organización de las Naciones Unidas, introduce

* Traducción de Carlos Vidal Prado (UNED) 
el mismo término en su propia fraseología: la dignidad. En resumen, como se ha dicho recientemente, se ha sustituido el binomio lipertad-propiedad, típico del Estado liberal, por el binomio libertad-dignidad humana, considerado más acorde al sistema de valores propio de las sociedades occidentales tras la Segunda Guerra Mundial ${ }^{1}$.

También tras la Segunda Guerra Mundial, en torno al término dignidad humana a largo plazo se ha producido un acuerdo unánime, sin que hubiese necesidad de hacer distinciones; término evocador, catalizador de consensos, indefinido en cuanto no requiere definición alguna, pero claro en su fuerza axiológica: el hombre en el centro de cualquier ordenamiento jurídico, nunca un medio para alcanzar fines que pueden ser nobilísimos, sino siempre -de acuerdo a la famosa definición kantiana- fin de la actuación de los poderes públicos y los esfuerzos conjuntos de los diversos componentes de la sociedad civil.

Ahora, transcurridas muchas décadas desde el renacimiento del mundo occidental de las tragedias de la guerra, la discusión sobre el significado de la dignidad humana también ha cobrado fuerza debido a los muchos avances científicos sobre los procesos del inicio de la vida, conectados a los fines más diversos, desde la investigación en nuevos medicamentos hasta el intento de sustituir los procesos de generación naturales con técnicas de reproducción asistida, todos muy prometedores para superar las barreras que la naturaleza y sus defectos parecían haber levantado ante la búsqueda de la perfección y la felicidad humanas. Con la evolución de los tiempos y las costumbres, en el ámbito de esta discusión, se ha sugerido recientemente la hipótesis -realmente no poco problemática- de que el concepto de la human dignity, en el plano jurídico, ya no tendría que considerarse una defensa frente a la barbarie, sino que acabaría siendo un concepto confuso, con múltiples (y muchas veces incluso contradictorios entre sí) significados, un argumento mordaz dirigido a evitar el problema de las argumentaciones detalladas, un big shot, ante el cual los jueces y abogados se pliegan mientras que las balanza de la justicia se inclina a favor de aquellos que invocan respectivamente la lesión y la tutela. La

${ }^{1}$ Por todos, recientemente G. AZZONI, Dignità umana e diritto privato, 2010 (ponencia en el Congreso "La dignità dell'uomo: testo e contesto" organizado por la Facoltà di Giurisprudenza, el Dipartimento di Scienze Giuridiche y la Scuola di dottorato in Scienze Giuridiche de la Università degli Studi di Modena e Reggio Emilia, 14 de octubre de 2010); la cita realizada es reconducible a a G.MONACO, "La tutela della dignità umana: sviluppi giurisprudenziali e difficoltà applicative", en Politica del diritto, 42 (2011), pp.45-77 a la que remitimos para las principales referencias doctrinales y jurisprudenciales; es útil también una mirada al panorama internacional, P. CAROZZA, "Human Dignity in Constitutional Adjudications", en Research Heandbook in Comparative Constitutional Law, Tom Ginsburg and Rosalind Dixon, eds., Edward Elgar 2011; C. MCCRUDDEN, "Human Dignity and Judicial Interpretation of Human Rights", European Journal of International Law, Vol. 19, N. 4, 2008, pp. 655-724; N. RAO, "Three concepts of dignity in Constitutional Law”, Notre Dame Law Review, Vol. 86, N. 1, 2011, pp. 183-271. 
dignidad humana: un concepto inútil, tan fundamental como indeterminado $\mathrm{y}$ tal vez incluso perjudicial?

2. Al igual que cualquier problema jurídico, fuente de discusión, las referencias para la reflexión no pueden ser otras que las controversias afrontadas y resueltas por la jurisprudencia.Entre otras muchas, y significativas para el tema que se está enfrentando aquí, ofrece un lugar especial el caso de Alemania sobre el abatimiento de los aviones que -tomados como rehenes por los terroristas- van a causar estragos entre civiles. Muchos otros supuestos pueden ser, además, recordados, como el tantas veces citado caso francés del lanzamiento del enano o aquél, originado también en Alemania, del pip-show o del caso de Omega. Recientemente, el debate se ha reavivado por una sentencia dictada por el Tribunal de Justicia en el caso Brüstle v. Greenpeace, resuelto el 18 de octubre $2011^{2}$. Sobre este caso se pretende fijar la atención en esta sede, siendo un caso reciente y por tanto de alguna manera sintentiza las tendencias actuales, no solamente en sede jurídica sino también sobre el plano filosófico y antropológico.

La disputa tenía como objeto -en el ámbito de la legislación europea sobre patentes- una solicitud de patentar un procedimiento mediante el cual el investigador Oliver Brüstle era capaz de crear células madre embrionarias, y por tanto totipotentes, células neuronales primigenias. Estas células, cuando se implantan en pacientes que sufren de enfermedades neurodegenerativas, permitirían poner a prueba nuevos tratamientos para las mismas, que como es notorio son incurables. Alternativamente, las células de este tipo podrían ser extraídas del cerebro en el momento de su formación, con la consecuencia de causar la destrucción de los fetos en fase de formación, contra todas las normas morales. La patente obtenida por Brüstle en 1997, sin embargo, fue cuestionada por la sección alemana de Greenpeace, que alegó que, para lograr estas células primigenias, era necesario destruir embriones humanos, conducta prohibida por la ley alemana. Y puesto que la disposición alemana reproduce exactamente una norma de la directiva europea sobre patentes y su correspondiente prohibición, en el curso de la controversia entre Greenpeace y Brüstle, el Tribunal Federal de Casación alemán elevó la cuestión en vía prejudicial al tribunal al Tribunal de Justicia para que se pronunciase sobre tres preguntas, la más interesante de las cuales se refiere a la interpretación del concepto de

${ }^{2}$ Para un planteamiento sintético del caso y de las cuestiones jurídicas a él inherentes, v. A. PESSINA, "Una sentenza per la dignità della persona", en Osservatore Romano, 20 octubre 2011; N. LAZZERINI, La nozione di embrione umano di cui alla direttiva 98/44/CE sulla protezione giuridica delle invenzioni biotecnologiche è una nozione autonoma di diritto dell'Unione: la sentenza della Corte di giustizia (Grande Sezione) nella causa C-34/10, Brustle, www.osservatoriosullefonti.it, fasc. 3/2011; V. ALTAMORE, La tutela dell'embrione, tra interpretazione giudiziale e sviluppi della ricerca scientifica, in una recente sentenza della Corte di Giustizia europea (C-34/10 Oliver Brustle contro Greenpeace e $V$., www.forumcostituzionale.it. 
embrión. En particular, dado que las células neuronales primigenias pueden extraerse no sólo de embriones humanos, sino también de óvulos humanos en los que haya sido insertado el núcleo de células humanas maduras (clonación) y de óvulos humanos estimulados mediante partenogénesis ${ }^{3}$, y, por supuesto, a partir de líneas celulares existentes, cuyo uso está permitido por la legislación alemana, siempre y cuando se hubieran producido antes de 2007, eranecesario determinar hasta qué punto se extendía el concepto jurídico de embrión para definir, en consecuencia, la extensión de la prohibición de patentarlo.

La Corte Europea ha respondido a la pregunta mediante la adopción de un concepto amplio de un embrión para ser aplicado en todos los Estados miembros por igual con el fin de prohibir las patentes de invenciones producidas sobre la base de todos los procesos mencionados, incluidos aquellos que no parecen dar lugar a la destrucción de embriones sino sólo a una manipulación del óvulo, induciéndolo a la mitosis. Una opción similar fue la adoptada en 2008 por la Enlarged Board of Appeal (EBA) de la Oficina Europea de Patentes (OEP); con la decisión G2/06 se había dispuesto en aquella sede que las células madre embrionarias humanas con capacidad de proliferación específica en forma indiferenciada, estabilidad y capacidad para diferenciarse regenerando tejidos de diferente origen y debidamente estimulados, no podía ser patentadas por cuanto se trataba de un proceso contrario al orden público y la moral y que afectaba al uso de embriones humanos con fines industriales y comerciales. La elección efectuada por la Oficina Europea es radical: en la motivación de la decisión se lee, de hecho, que la integridad y la dignidad del embrión humano tiene prioridad sobre cualquier uso, incluyendo el propósito de la investigación médica ${ }^{4}$.

3. En estos dos casos Europa, por boca de sus estructuras administrativas y sus tribunales, parece ir más allá de las Columnas de Hércules: adoptando un enfoque global de la cuestión de la protección de la dignidad humana, los jueces la extienden no sólo -como es natural-a los óvulos humanos desde la fecundación, sino también a cualquier óvulo humano inducido a dividirse y desarrollarse con cualquier método. El límite es por lo tanto particularmente amplio y deja fuera solamente las células madre en cuanto tales, cuya tutela se deja en manos de las decisiones de los tribunales nacionales, subsistiendo en esta materia -siempre según el Tribunal- la falta de certeza científica acerca de su naturaleza. A contraris, por lo tanto, los mismos óvulos fecun-

${ }^{3}$ Véanse las últimas investigaciones sobre células madre embrionarias de Paolo De Coppi y de Robert Lanza publicadas en la revista Nature, entre ellas "Isolation of amniotic stem cell lines with potential for therapy", in Nature Biotechnology, 25, 2007, pp. 100106.

${ }^{4}$ Sobre la decisión y sus aspectos innovativos, ver C. GERMINARIO, "Brevettazione delle cellule staminali embrionali umane: divieto o legittimazione?" en Diritto Industriale 2009, 2, 10. 
dados o en todo caso inducidos a dividirse serían considerados, sobre la base de certezas científicas, como parte del concepto de embriones y dignos de la misma protección que pertenece a todo ser humano 5 .

De esta manera el Tribunal acoge las conclusiones el Abogado General Yves Bot; en sus conclusiones se encuentra ya una clara toma de posición a favor de una interpretación uniforme del concepto de embrión humano en el ámbito comunitario, en nombre de la dignidad del mismo, sea tan grande como sea posible. Básicamente, en la actualidad, para el derecho europeo se consideran etapas de desarrollo de la vida humana afectadas por el proceso de tutela garantizada por la ley, las que se refieren a óvulos humanos fecundados, y de óvulos humanos no fecundados pero convertidos en objeto de un procedimiento para su desarrollo.

4. Central para la opción asumida en sede jurisdiccional ha sido el concepto científico de totipotencia, considerada la característica primigenia del ser humano, base para el reconocimiento de la protección jurídica del mismo; a partir de estas células se desarrolla, en efecto, sin solución de continuidad todo el ser humano en su corporeidad. Otros estados sucesivos del desarrollo del ser humano, como la anidación, que parte de la doctrina considera el umbral para activar la protección jurídica ${ }^{6}$, se consideran irrelevantes, así como irrelevante ha sido considerado el hecho de que los embriones hubieran sido creados con intenciones diversas a la inducción de un embarazo ${ }^{7}$.

Es sobre el concepto de totipotencia sobre el que vale la pena, por tanto, detenerse, sobre todo a la luz de las muchas críticas formuladas en sede científica y jurídica respecto a ello. El concepto de totipotencia, de hecho, es característico de las células que se desarrollan inmediatamente después de la fecundación, cuando el óvulo fecundado comienza a dividirse dando lugar al

\footnotetext{
${ }^{5}$ Se han avanzado críticas sobre la subsistencia de una certeza científica y de una unanimidad de concepciones entre los Estados miembros con relación al concepto de embrión. Según Dereder, mientras hay consenso en el ámbito de la Unión sobre el hecho de que no se pueden patentar invenciones contrarias al orden público y a la moral (buenas costumbres), no existe consenso sobre el concepto de embrión (ver en Alemania el artículo 8, apartado 1de la Ley sopre la protección del embrión y las declaraciones del Comité ético nacional de 2004, sobre la patentabilidad de descubrimientos biotecnológicos alcanzados usando material biológico de origen humano. Cfr. L. LAIMBÖCK, H.G. DEDERER, Der Begriff des "Embryos" im Biopatentrecht. Anmerkung zu den Schlussanträge von GA Yves Bot v. 10 März 2011, Rs. C-34/10 -Brüstle. Zugleich eine Kritik des Kriteriums der "Totipotenz", en GRURInt 2011,661- beck online.

${ }^{6} \mathrm{El}$ argumento adoptado para sostener esta tesis es que, sin anidación, no sería posible el nacimiento; y sin embargo la anidación resulta ser un elemento extrínseco respecto al embrión, un acontecimiento externo a él subre el que el hombre puede interferir, un lugar en el cual él viene situado y que determinaría la dignidad.

${ }^{7}$ Sobre la base del argumento según el cual el concebido sería tal si fuese querido por la pareja; de nuevo una argumentación de carácter meramente subjetivo, que hace depender la dignidad del embrión de la voluntad de otros de atribuirle una determinada finalidad.
} 
blastocisto, un conjunto de células totipotentes, que se distinguen en trofoblasto, que dará origen lugar a los anexos del embrión, y el nodo o botón embrional, del cual se desarrollará el nuevo organismo. Por lo tanto, la totipotencia tiene dos aceopciones: es totipotente una célula a partir de la cual se desarrolla un organismo completo o es totipotente una célula capaz de generar todos los tipos de células, incluyendo la que proceda del trofoblasto, a partir de la que no se desarrolla el organismo, sino la placenta . La solicitud de patente había asumido el segundo significado, y por tanto las células de partida de Brüstle sí podrían desarrollarse en cualquier tipo de tejido, pero no en un individuo completo, ya que podrían ser extraída del trofoblasto y no del embrión en el sentido estricto.

Sobre esta base, la opción de considerar no patentables todos los tipos de células totipotentes de manera indiscriminada, ha sido objeto de críticas y se ha solicitado que el mismo concepto de la totipotencia sea aclarado en sede científica y jurídica para investigar las implicaciones éticas de dos tipos diferentes. Pero estas críticas, que también deben ser consideradas con atención, no resisten la consideración que subyace en la defensa radical de la vida desde su inicio, aquella según la cual el proceso de división del óvulo es considerado el momento genético de la nuevo organismo y, por tanto, el óvulo que comienza a dividirse debe ser considerado digno de protección y no destructible, ni siquiera para extraer las células totipotentes que en perspectiva no entrarían materialmente en el nuevo organismo, sino sólo en sus anexos, pero que por lo demás son fundamentales para el desarrollo de la vida humana.

De esta manera se ha movido el Tribunal, y esto debe considerarse muy importante para una sociedad en la que la manipulación genética parece haberse convertido en aceptable teniendo en cuenta los posibles desarrollos positivos de las correspondientes investigaciones; también muy importante, porque -de esta manera- se toma una postura en contra de tesis que se están difundiendo relativas a los procesos de desarrollo del ser humano sobre la base de la división en fases de dichos procesos y en favor de la idea de que el cuerpo humano se desarrolla, por el contrario, de acuerdo a un proceso integral que no conoce solución de continuidad ${ }^{8}$. Según Dederer, que ha dado argu-

${ }^{8}$ El Tribunal habrá quizá tenido presente la serie de argumentos que se han ido avanzando a favor de la unidad del proceso de generación del cuerpo humano maduro. Se trata de los llamados SKIP-Argumente, en otras palabras el argumento de la especie (según el cual la célula totipotente pertenece ya a la familia humana), el de la continuidad (Kontinuität-Argument, según el cual faltan elementos de división claros entre las diversas fases, el de la identidad (la célula totipotente sería in nuce idéntica al bebé en el que derivará) y de la potencialidad (según el cual la célula totipotente y solamente ella tiene la capacidad de desarrollarse, en determinadas condiciones, hasta convertirse en un individuo completo). Quien por el contrario sostiene que es la anidación el episodio decisivo del que surge la obligación de la tutela jurídica argumenta diciendo que este es un episodio fundamental del desarrollo (un salto de calidad) porque, si se partiese de las células madre totipotentes 
mentos durante mucho tiempo en contra de la opinión sostenida por la sentencia, por ejemplo, no sería razonable decir, como hace el Abogado General en sus conclusiones, que "las células totipotentes ... representan la primera etapa del cuerpo humano en que se convertirán, por lo que que han de ser considerados como embriones..."; sería necesario, por el contrario, distinguir entre una primera fase de este desarrollo en la que se forma el embrión, fase, a su vez, en la cual sería distinto el proceso de formación de la placenta respecto al de la formación del embrión en cuanto tal, una segunda fase en la que el embrión se anida y una tercera fase en la que el embrión entra en la etapa fetal. Si se reconociesen realmente diferentes fases, también podría ser divrsa y graduada la relativa tutela jurídica, como de hecho en parte ya está sucediendo.También de acuerdo con este autor, no habría coherencia entre la primera afirmación del Abogado General (células totipotentes como primera etapa del desarrollo del cuerpo humano) y la segunda... (que la misma pertenece al género "embrión"), sino que sería necesario, por contra, rediscutir la atribución de la denominación de embrión a esta primera etapa que podría, al contrario, ser más fácil de definir de otra manera.

5. Teorías gradualistas y teorías fundamentalistas se confrontan, así, sobre el terreno, complejo, de la interpretación de los procesos de formación de la vida humana, el cuerpo humano, la vida en cuanto tal y la humanidad como carácter distintivo de nuestra especie; la sentencia que estamos examinando muestra una clara toma de postura clara a favor de las segundas.

Este resultado debe, sin duda, ser valorado y saludado como fruto de gran importancia, basado sobre la prioridad de opciones morales fundamentales respecto a las técnico-científicas; en esta perspectiva es útil, como ya se mencionó, la referencia a la dignidad humana como un concepto que no es susceptible de graduaciones, concepto plenamente jurídico, pero al mismo tiempo, indicativo de una tabla de valores fundada sobre la preeminencia del ser humano como tal, en comparación con otros intereses menos fundamentales. La opción opuesta, la de carácter gradualista, no se sustrae a la impresión de haber sido formulada con el único propósito de establecer grados de tutela jurídica: no la sustancia del embrión humano, sino la necesidad de graduar su tutela, incluso en favor de los intereses materiales o la investigación, sería

y no de la anidación, la mujer que se somete a procesos de fecundación asistida no podría elegir si hacerse implantar el embrión o no; por el contrario, la mayoría de las legislaciones permite a la mujer elegir si someterse a la implantación tras la fecundación, en nombre del derecho a la autodeterminación femenina respecto al propio cuerpo (Art. 2, apartado 2, frase nr.1 GG). Sería sin embargo necesario sancionar una obligación de implantar si antes de la anidación las células fecundadas y en fase de primera diferenciación en vitro fuesen titulares de una plena tutela jurídica a ellas atribuida por razón de su derecho a la vida y a la dignidad humana. Y, verdaderamente, aquí se toca un tema crucial de las modernas legislaciones restrictivas en la cuestión del derecho a la vida, visto que dichas legislaciones, precisamente por su naturaleza restrictiva, se muestran en evidente contraste con las ya ampliamente difundidas legislaciones en materia de aborto. 
la opción básica realizada por los defensores de esa posición, también sobre la base del hecho, por todos contrastable, de que la misma vida después del nacimiento conoce fases de desarrollo, que sin embargo no afectan a la sustancia de la vida misma y su protección.

6. Una posición análoga a la mantenida en este caso había sido, por lo demás, sostenida y argumentada ya en la Declaración Final de la XII Asamblea General de la Academia Pontificia para la Vida, emitida a la conclusión del Congreso Internacional sobre "El embrión humano en la fase de pre-implantación. Aspectos científicos y consideraciones bioéticas “, que se celebró en Roma en febrero de $2006^{9}$. Esta declaración, basada sobre los más modernos avances de la embriología, había establecido que las características de continuidad, gradualidad y coordinación, propias del desarrollo del organismo humano, ya están presentes desde el inicio del proceso de mitosis del óvulo, es decir, en esa etapa que precede a la formación del blastocisto y se llama la fase de mórula; se afirma en dicha sede que "el conjunto de estas tendencias constituye la base para interpretar el cigoto ya como un organismo primordial (organismo unicelular) que expresa coherentemente sus potencialidades de desarrollo a través de una continua integración primero entre los diversos componentes internos y luego entre las células a que da lugar progresivamente".

En consecuencia, el estatus moral del embrión puede ser definitido no con base en una división por etapas de su desarrollo, que se identifican sobre la base de criterios extrínsecos al embrión mismo, criterios por su naturaleza convencionales y arbitrarios, sino, más bien, a partir de su propia naturaleza de embrión. Partiendo de este elemento de carécter científico, la Declaración sigue diciendo que el embrión, en la fase de preimplantación, es un ser de la especie humana, es un ser individual en cuanto posee en sí la finalidad de desarrollarse como persona y, en conjunto, la capacidad intrínseca de operar tal desarrollo.

En sustancia -y más allá de cualquier intento de determinar en este individuo la característica de persona humana, característica que se muestra como de naturaleza filosófica y no estrictamente científica- la dignidad de este ser se deriva no de elementos interpretativos, sino del hecho mismo de que, visto que se está en la presencia de un organismo humano, de ello se deriva de la necesidad de garantizar el pleno respeto de su integridad y dignidad, y por lo tanto, cualquier conducta que ponga en peligro el derecho a la vida se presenta como gravemente inmoral. Todas estas afirmaciones son de gran importancia,

\footnotetext{
${ }^{9}$ Pero ver también la amplia reflexión sobre el concepto de persona planteada por R. Spaemann, según el cual, de modo muy sintético "puede y debe tenerse un único criterio para la personalidad: la pertenencia biológica al género humano. Por esto también el inicio y el fin de la existencia de la persona no pueden separarse del inicio y el fin de la vida humana". Citado por E. SGRECCIA, Manuale di bioetica, Vol. I, Fondamenti ed etica biomedica, Vita e Pensiero, Milano 2007, p. 137.
} 
tanto en el plano de los contenidos, como en el del método que permite llegar a estas conclusiones. En contra de cualquier acusación de dogmatismo, el camino que se recorre para definir la naturaleza del embrión se basa sobre elementos de hecho comprobables por todos y sobre los que se ha establecido la frontera de la investigación científica. Hechos y no opiniones, por lo tanto, hechos que traen como consecuencia opciones morales y jurídicas dotadas de una sólida base no dogmática sino racional.

5. Conforme a lo expuesto, se destaca cómo existe una sustancial coincidencia entre las opciones de la Declaración, formulada en 2006, y las que se realizan en sede europea cinco años después. Y, sin embargo, hay que decir también que -a pesar de ello- la cuestión no puede ciertamente considerarse como definitivamente cerrada. Antes bien, la cuestión abre una nueva serie de problemáticas posteriores que sería cuando menos miope ignorar. En efecto, no es esta concepción siempre la dominante ni en los ordenamientos nacionales ni en el ámbito europeo. En otros asuntos, distintos del campo de las patentes (y por lo tanto del disfrute comercial exclusivo por parte del titular de la patente) se han realizado opciones jurídicas alternativas a la presente; asimismo es con éstas con las que es necesario enfrentarse si no se quiere poner excesivo énfasis sobre el presente caso. En particular, en opinión de quien esto escribe, es necesario considerar que, frente a la afirmación -más que compartible - de la unidad del proceso de formación de la vida, si no otra cosa, al menos sobre la base de un principio de precaución, en el sector de la tutela de los derechos parecen ser otras las lógicas dominantes; aquí los derechos de los embriones y los fetos se comparan con los derechos de las madres y padres de familia, lo que supone en la mayoría de los casos que sucumben los primeros frente a los segundos; lo cual no puede más que crear desequilibrios, como si, en última instancia, se confiriese al embrión -que también incluye al feto, a los fines de la patentabilidad- una protección mucho más fuerte que la del feto en la perspectiva de la tutela de sus derechos, reales o potenciales, con respecto a los derechos de los demás. ¿Cómo, entonces, comprender y justificar las decisiones tomadas en esta sede? Dos pueden ser las consideraciones sobre las que reflexionar ${ }^{10}$.

La primera: es necesario concentrarse sobre el hecho de que el progreso científico en el campo biotecnológico, cuando afecta al individuo incluso en el momento en que surge, pone en peligro toda la especie humana, con consecuencias que deben considerarse mucho más peligrosas que la elección con-

${ }^{10}$ Todavía más difícil resulta compatibilizar las afirmaciones de la sentencia que estamos examinando con las normas éticas fundamentales del VII Programa Marco sobre la investigación, desarrollo tecnológico y comunicación /2007-2013, según las cuales es posible que la Unión financie con sus medios investigaciones que tengan por objeto células madre embrionarias humanas, independientemente de su proveniencia; además en muchos Estados no se considera contrario al orden público y a la moralidad producir células madre embrionarias de embriones humanos. 
creta de un individuo concreto ( la madre) que afirma sus propios derechos con relación al hijo en su vientre o al hijo deseado y buscado por todos los medios puestos a disposición por el progreso científico y médico. Con lo cual parece casi que la esfera de los derechos, con sus normas y sus lógicas argumentativas ya muy arraigadas, es más permisiva respecto a otros sectores del ordenamiento en los que domina una lógica más técnica y por lo tanto más objetiva y generalizada.

En otras palabras, la norma según la cual no se puede patentar el cuerpo humano como un todo o partes de él, siendo norma objetiva del ordenamiento, tendría un alcance más radical respecto a la lógica de la ponderación según la cual el derecho (subjetivo) a tener un hijo prevalece sobre el derecho (igualmente subjetivo, pero menos "pesado" que el primero) del embrión formado en probeta a mantener su integridad o incluso del feto a ver tutelada la propia capacidad de desarrollarse hasta convertirse en un hombre completo; este último derecho ve debilitada su tutela si se sitúa en confrontación con la libertad de elección o el derecho a la salud de la madre.

La segunda: patentar comporta, como todos saben, pasra el titular del relativo derecho la facultad de sacar de la propia invención en exclusiva todos los beneficios que se derivan de su uso industrial y comercial. En consecuencia, la defensa de la dignidad (es decir, de lo específico del ser hombres) de la vida humana (y no sólo del desarrollo corpóreo del hombre, sino de contenido que este desarrollo contiene en sí mismo) en todas sus fases, desde la etapa primitiva hasta la de plena madurez, no compite con otros derechos, sino más bien con la posibilidad de conseguir ventajas comerciales, industriales o progresos científicos (estos últimos igualados a los primeros com gran realismo por parte del Tribunal de Justicia) de las invenciones relacionadas con ella: competencia desigual, que considera por tanto la prevalencia absoluta de la mencionada tutela.

En pocas palabras, a diferencia de los EE.UU., Europa parece mantener una estimación reciente de la dignidad humana que no está sujeta a las lógicas del mercado o del progreso científico sin ningún tipo de condiciones; antes bien, precisamente la dignidad humana, considerada por muchos como un principio inútil, sirve en el presente caso para marcar la diferencia entre la tendencia a ponderar y la necesidad de afirmar con claridad los fundamentos de la propia civilización, no comercial, sino digna. En este sentido, Europa puede redescubrirse a sí misma- todavía en nombre de su persistente humanismo - más determinada por la ética y que por otros intereses económicos y configurarse como una tierra donde, bajo las cenizas de radicalismo libertario, conserva la calidez de la tradición iluminista de su norma moral fundamental de origen kantiano, aquella según la cual el hombre nunca puede ser considerado como un medio para alcanzar incluso los más nobles propósitos, sino siempre y sólo un fin. 